\title{
Recovering Energy at Entry of Natural Gas into Customer Premises by Employing a Counter-Flow Vortex Tube
}

\author{
M. Farzaneh-Gord* and M. Kargaran \\ The Faculty of Mechanical Engineering, Shahrood University of Technology, Shahrood - Iran \\ e-mail: mahmood.farzaneh@yahoo.co.uk-m.kargaran@gmail.com \\ * Corresponding author
}

\begin{abstract}
Résumé - Récupération d'énergie à l'arrivée du gaz naturel dans les installations des usagers grâce à l'emploi d'un tube Vortex à contre-courant - La réduction de la pression de gaz naturel entre les conduites de distribution haute pression et les installations des usagers est aujourd'hui assurée par des vannes de réduction de pression. Ce dispositif entraîne une perte importante du contenu énergétique du gaz. Les installations des usagers consommant trop peu de gaz naturel pour envisager d'avoir recours à des dispositifs d'expansion, notre étude explore les avantages potentiels de l'utilisation d'un tube Vortex pour la réduction de la pression de gaz naturel. Il s'agit de remplacer la vanne de réduction de pression par un tube Vortex dans le dispositif de réduction de la pression de gaz naturel et de tirer profit de la capacité de refroidissement produite. L'étude expérimentale avait pour objectif de déterminer l'effet du diamètre de l'orifice froid ainsi que de l'utilisation de l'air et du gaz naturel comme fluides sur la production d'énergie dans le tube Vortex à contre-courant. Le taux de récupération de l'énergie est déterminé à partir des mesures expérimentales.
\end{abstract}

\begin{abstract}
Recovering Energy at Entry of Natural Gas into Customer Premises by Employing a Counter-Flow Vortex Tube - Throttling valves are currently utilised to reduce high-pressure natural gas flowing through the distribution pipeline to the working level of customers' equipment. This wastes valuable energy of the gas. Due to low natural gas consumption at customer premises, it is not feasible to utilise expansion machines. In this study, a new idea is proposed to take advantage of the Vortex Tube and natural gas pressure reduction. The idea is to replace the throttling valve with a Vortex Tube in the natural gas pressure reduction system and take advantage of the generated cooling capacity. An experimental investigation was made to determine the effects of the cold orifice diameter and the energy separation of the counter-flow Vortex Tube when air and natural gas are used as the fluid. The energy separation was investigated by use of the experimentally obtained data.
\end{abstract}




\section{NOMENCLATURE}

\begin{tabular}{|c|c|}
\hline $\mathrm{C}_{6}+$ & $\begin{array}{l}\text { All hydrocarbon compounds with more than } 5 \\
\text { carbons in their chemical formula ( } \mathrm{kmol} / \mathrm{kmol})\end{array}$ \\
\hline$D$ & Vortex Tube inlet diameter (mm) \\
\hline$d$ & Cold orifice diameter (mm) \\
\hline$L$ & Vortex Tube length (mm) \\
\hline$L_{h}$ & Hot Tube length (mm) \\
\hline$L_{c}$ & Cold Tube length (mm) \\
\hline NG & Natural Gas (-) \\
\hline$P$ & Pressure (bar) \\
\hline$T$ & Temperature $\left(\mathrm{K}\right.$ or $\left.{ }^{\circ} \mathrm{C}\right)$ \\
\hline RHVT & Ranque-Hilsch Vortex Tube (-) \\
\hline VT & Vortex Tube (-) \\
\hline$\delta$ & Inlet nozzle diameter (mm) \\
\hline$\Phi$ & Conical controlling valve angle (degree) \\
\hline$\dot{m}$ & Mass flow rate $(\mathrm{kg} / \mathrm{s})$ \\
\hline$\mu_{c}=\frac{\dot{m}_{c}}{\dot{m}_{i}}$ & Cold mass fraction (-) \\
\hline$\Delta T_{c}=T_{i}-T_{c}$ & Cold temperature difference $\left(\mathrm{K}\right.$ or $\left.{ }^{\circ} \mathrm{C}\right)$ \\
\hline$\Delta T_{h}=T_{h}-T_{i}$ & Hot temperature difference $\left(\mathrm{K}\right.$ or $\left.{ }^{\circ} \mathrm{C}\right)$ \\
\hline$\dot{Q}_{c}=\dot{m}_{c} \Delta h_{c}$ & Cooling capacity $(\mathrm{Kw})$ \\
\hline$q_{c}$ & Specific cooling capacity $(\mathrm{kJ} / \mathrm{kg})$ \\
\hline$\eta_{i s}$ & Isentropic efficiency (-) \\
\hline
\end{tabular}

\section{Subscript}

1 Inlet gas condition of the pressure drop system

2 Outlet gas condition of the pressure drop system

c Cold stream

h Hot stream

i Inlet stream

\section{INTRODUCTION}

When a natural-gas distribution pipeline nears a customer, the high-pressure gas needs to be reduced to working level. Throttling valves are currently utilised to reduce the gas pressure. This causes the valuable energy of the gas to be wasted. There is the possibility of using expansion machines instead of throttling valves, but due to low consumption, high installation cost and their reliability, it is not feasible to install expansion machines. The main candidate to replace a throttling valve is a Vortex Tube (VT). The Vortex Tube is a simple device without a moving part which is capable of separating hot and cold gas from a higher pressure inlet gas (Cockerill, 1995; Eiamsa-ard and Promvonge, 2008; Lewins and Bejan, 1999).

The VT, also known as a Ranque-Hilsch Vortex Tube (RHVT), was first discovered in 1933 by Ranque, and the
German physicist Hilsch improved the design (1947), who provided comprehensive experimental and theoretical studies intended to improve the efficiency of the Vortex Tube. He methodically inspected the effect of the inlet pressure and the geometrical parameters of the VT on its performance and presented a possible explanation of the energy separation process. There have been a lot of researchers since then who have studied the Vortex Tube aiming to enhance its performance. Takahama et al.'s (1979) study resulted in several formulas for determining the performance and efficiency of VT under a variety of operating conditions, which induced the optimum ratios of VT dimensions corresponding to the highest efficiency. Silverman (1982) questioned whether the VT is a violation of the second law of thermodynamics or not. Lin et al. (1990) carried out an experimental investigation to study the heat transfer behaviour of a water-cooled VT with air. Piralishvili and Polyaev (1996) carried out experimental investigations into this effect in the so-called double-circuit VT. The possibility of constructing a doublecircuit VT refrigeration machine as efficient as a gas expansion system was demonstrated. Nimbalkar and Muller (2009) presented the results of a series of experiments focusing on various geometries of the "cold-end side" for different inlet pressures and cold fractions. The experimental results indicated that there is an optimum diameter of the cold-end orifice for achieving maximum energy separation. It was observed that for cold fractions less than or equal to $60 \%$, the effect of the cold-end orifice diameter is negligible, and above $60 \%$ cold fraction it becomes prominent. The results also show that the maximum value of the performance factor was always reachable at a $60 \%$ cold fraction irrespective of the orifice diameter and the inlet pressure.

Dincer et al. (2009) have studied the effects of position, diameter and angle of a mobile plug, located at the hot outlet side experimentally to get the best performance. The most efficient (maximum temperature difference ) combination of parameters is obtained for a plug diameter of $5 \mathrm{~mm}$, and tip angle of $30^{\circ}$ or $60^{\circ}$, by keeping the plug in the same position, and letting the air enter into the Vortex Tube through 4 nozzles. Increasing the inlet pressure beyond $380 \mathrm{kPa}$ did not cause any appreciable improvement in the performance.

Stephan et al. (1983) measured the temperature profiles at different positions along a Vortex Tube axis and concluded that the length of the Vortex Tube would have an important influence on the transport mechanism inside.

Saidi and Valipour (2003) presented information data on the classification of the parameters affecting Vortex Tube operation. In their study, the thermophysical parameters such as inlet gas pressure, type of gas and cold gas mass ratio, moisture of inlet gas, and the geometrical parameters, i.e., diameter and length of main Tube diameter of the outlet orifice and shape of the entrance nozzle, were designated and studied.

Orhan and Muzaffer (2006) have carried out a series of experiments to investigate the effects of the length of the 
pipe, the diameter of the inlet nozzle, and the angle of the control valve on the performance of the counterflow Vortex Tubes for different inlet pressures. Experiments showed that the higher the inlet pressure, the greater the temperature difference of the outlet streams. It was also shown that the cold fraction is an important parameter influencing the performance of the energy separation in the Vortex Tube. Optimum values for the angle of the control valve, the length of the pipe and the diameter of the inlet nozzle were obtained.

There have been other media than air used as the working fluid. Balmer (1988) applied liquid water as the working medium. It was found that when the inlet pressure is high, for instance 20 50 bar, the energy separation effect still exists. So it proves that the energy separation process exists in an incompressible Vortex flow as well. Hydrocarbons have also been used as the working fluid. Two-phase propane was used as the working fluid by Collins and Lovelace (1979). It was found that when the degree of dryness of the liquid and gaseous propane is higher than 0.80 , a significant temperature difference is maintained. With two-phase working fluid, the degree of dryness is an important parameter; when the degree of dryness is larger than a critical value, energy separation occurs. In 2002 the VT system was used to enrich the concentration of methane by Kulkarni and Sardesai (2002). They tried to separate methane and nitrogen gases using VT. This particular separation, or the resulting enrichment of methane concentration, has applications in the mining industry. In 2004, Poshernev and Khodorkov (2004) suggested utilising the VT as a pre-cooling system for natural gas liquefaction. The conical Vortex Tube was further investigated theoretically by Khodorkov et al. (2003) for chemical applications.

Eiamsa-ard and Promvonge (2008) presented a complete overview of the past investigations of the mean flow and temperature behaviours in a turbulent Vortex Tube in order to understand the nature of the temperature separation or Ranque-Hilsch effect. They have proposed optimum values for the cold orifice to the VT inlet diameter $(d / D)$ of 0.5 , the angle of the conical control valve of 50 degrees, the length of the Vortex Tube to the VT inlet diameter $(L / D)$ of 20 and the diameter of the inlet nozzle to the VT inlet diameters $(\delta / D)$ of 0.33 for air as the working fluid.

In order to understand the flow structure within the VT, the VT has also been subjected to Computational Fluid Dynamic (CFD) research. Skye et al. (2006) have presented a comparison between the performance predicted by a CFD model and experimental measurements taken using a commercially available Vortex Tube. Specifically, the measured exit temperatures into and out of the Vortex Tube are compared with the CFD model. The comparison between the CFD model and the measured experimental data yielded promising results relative to the model's ability to predict the power separation. Aljuwayhel et al. (2005) have employed a CFD model to investigate the energy separation mechanism and flow phenomena within a counter-flow Vortex Tube. A two-dimensional axi-symmetric CFD model has been developed that exhibits the general behaviour expected from a Vortex Tube. The model results are compared with experimental data obtained from a laboratory Vortex Tube operated with room temperature compressed air. The model shows that the Vortex Tube flow field can be divided into three regions that correspond to: flow that will eventually leave through the hot exit (hot flow region), flow that will eventually leave through the cold exit (cold flow region), and flow that is entrained within the device (recirculating region).

To our knowledge, no previous work has been carried out to investigate the thermal behaviour of natural gas as it passes through a VT. In this work an experimental study was carried out to investigate Natural Gas (NG) temperature behaviours in a VT. The effects of the VT cold orifice diameter on the VT thermal separation are also studied. Further, the amount of cooling capacity created by NG as it passes through a VT was calculated. As discussed above, it will have potential applications in the gas industry and energy saving.

\section{THE CURRENT AND PROPOSED PRESSURE REDUCTION SYSTEMS}

Natural gas is delivered to the customers through the distribution pipeline at approximately 5 bar in Iran (and probably in most countries) but all NG equipment consumes it at a working pressure of slightly higher than 1 bar. Currently, throttling valves are employed to reduce the pressure through a constant enthalpy process. A schematic diagram of a current typical reduction system is shown in Figure 1. Inlet gas has a high pressure $\left(P_{1}=5 \mathrm{bar}\right)$ and temperature $\left(T_{1}\right)$, which is typically the ambient temperature. The standard outlet pressure is approximately 1 bar and the output temperature $\left(T_{2}\right)$ is approximately $2 \mathrm{~K}$ lower than inlet temperature. As the temperature reduction is low, it is not possible to take advantage of this pressure reduction. The VT is a potential candidate to replace the current system as a reliable system. In the case of replacement, it would be possible to produce refrigeration, especially for high buyers such as hotels and restaurants.

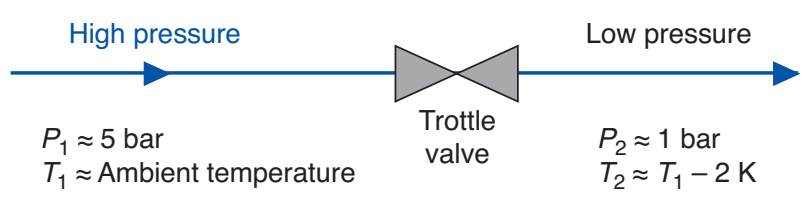

Figure 1

A schematic diagram of a current typical pressure reduction system. 


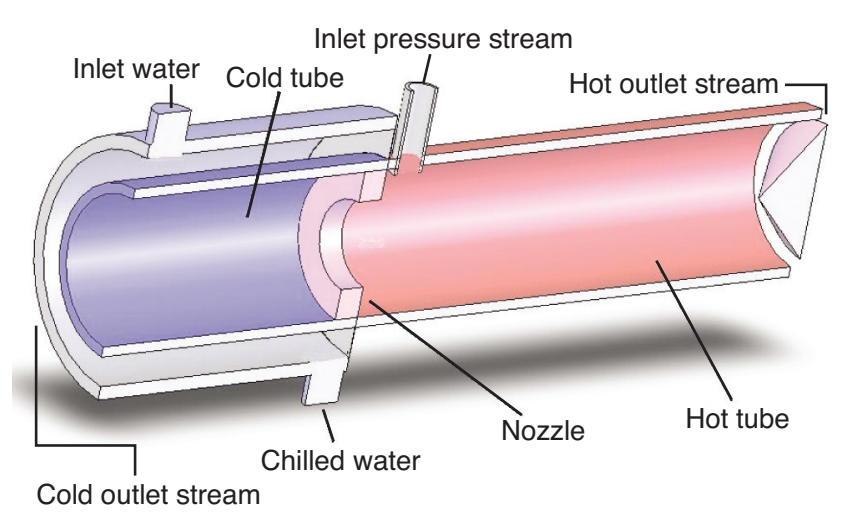

Figure 2

The schematic diagram of the proposed counter-flow VT combined with a heat exchanger.

In this study, the throttling valve is proposed to be replaced by a combined Vortex Tube and heat exchanger as shown in Figure 2. The high-pressure natural gas is introduced at the inlet port and expanded through the counter-flow VT. The gas is separated into two streams and they flow through the hot and cold Tubes. The water is circulated within the cold Tube as shown in Figure 2. As the water is circulated, its temperature drops due to heat exchange with the cold stream. Now the chilled water is available for refrigeration purposes. Finally, the two low-pressure natural gas streams could be combined and delivered to the equipment as in the current system.

\section{CHEMICAL COMPOSITION OF NATURAL GAS}

Natural gas composition (mixture) varies with location, climate and other factors. The gas is refined before flowing into the pipelines. Gas consumed in Shahrood (where the experiments were carried out) is totally processed in the Khangiran refinery. Table 1 details the chemical composition of the gas.

\section{THE VORTEX TUBE PARAMETERS}

There are a few important parameters affecting the VT thermal behaviour which should firstly be introduced.

\subsection{The Geometrical Parameters}

Figure 3 shows a schematic diagram of the counter-flow Vortex Tube which was constructed and used in this study. As shown in Figure 3, the geometrical parameters are inlet VT diameters $(D)$, cold orifice diameter $(d)$, inlet nozzle
TABLE 1

Chemical composition of natural gas from the Khangiran refinery

\begin{tabular}{c|c|c}
\hline Component & Chemical formula & Percent mole fraction \\
\hline Carbon dioxide & $\mathrm{CO}_{2}$ & 0.055 \\
\hline Nitrogen & $\mathrm{N}_{2}$ & 0.428 \\
\hline Methane & $\mathrm{CH}_{4}$ & 98.640 \\
\hline Ethane & $\mathrm{C}_{2} \mathrm{H}_{6}$ & 0.593 \\
\hline Propane & $\mathrm{C}_{3} \mathrm{H}_{8}$ & 0.065 \\
\hline Isobutane & $\mathrm{C}_{4} \mathrm{H}_{10}$ & 0.015 \\
\hline Normal butane & $\mathrm{C}_{4} \mathrm{H}_{10}$ & 0.034 \\
\hline Isopentane & $\mathrm{C}_{5} \mathrm{H}_{12}$ & 0.026 \\
\hline $\mathrm{C}_{6}+$ & $\mathrm{C}_{6}+$ & 0.125 \\
\hline & & Total $=100 \%$ \\
\hline
\end{tabular}

Source: Khangiran refinery website.

diameter $(\delta)$, conical controlling valve angle $(\Phi)$, cold tube length $\left(L_{c}\right)$ and hot tube length $\left(L_{h}\right)$. Table 2 shows the detailed geometrical parameter dimensions used in this study. These values are selected based on proposed optimum values by Eiamsa-ard and Promvonge (2008). As can be seen, the cold orifice diameter was varied from $8 \mathrm{~mm}$ to $17.7 \mathrm{~mm}$.

\section{TABLE 2}

The geometrical parameters and their values

\begin{tabular}{l|c|c|c|c|c|c|c}
\hline Parameter & $\begin{array}{c}D \\
(\mathrm{~mm})\end{array}$ & $\begin{array}{c}d \\
(\mathrm{~mm})\end{array}$ & $\begin{array}{c}\delta \\
(\mathrm{mm})\end{array}$ & $\begin{array}{c}\Phi \\
(\text { degree })\end{array}$ & $\begin{array}{c}L_{c} \\
(\mathrm{~mm})\end{array}$ & $N$ & $\begin{array}{c}L_{h} \\
(\mathrm{~mm})\end{array}$ \\
\hline Value & 25 & 8 & 8 & 50 & 50 & 1 & 769 \\
\hline & & 12.1 & & & & & \\
\hline & & 17.7 & & & & & \\
\hline
\end{tabular}

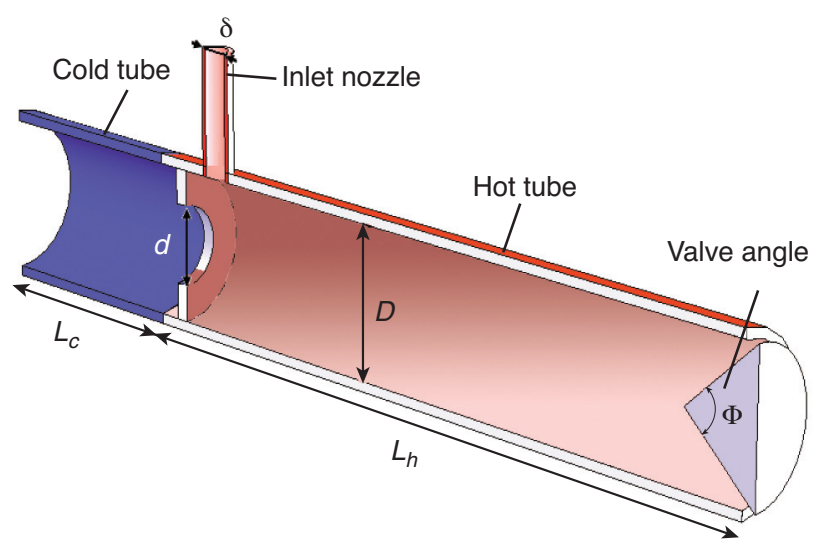

Figure 3

The schematic diagram of a counter-flow Vortex Tube. 


\subsection{The Flow Parameters}

As mentioned by Eiamsa-ard and Promvonge (2008), the most important flow parameter is believed to be cold mass fraction, which is defined as:

$$
\mu_{c}=\frac{\dot{m}_{c}}{\dot{m}_{i}}
$$

where $\dot{m}_{c}$ and $\dot{m}_{i}$ are the mass flow rates at the inlet of the Vortex Tube and at the cold outlet, respectively. The other flow parameters are:

- the cooling $\left(\Delta T_{c}\right)$ and the heating $\left(\Delta T_{h}\right)$ effects of the Vortex Tube are defined as follows, respectively:

$$
\begin{aligned}
\Delta T_{c} & =T_{i}-T_{c} \\
\Delta T_{h} & =T_{h}-T_{i}
\end{aligned}
$$

where $T_{i}$ is the inlet stream temperature, $T_{c}$ is the outlet stream temperature of the cold end and $T_{h}$ is the outlet stream temperature of the hot end;

- the performance of the Vortex Tube was defined as the difference between the heating effect and the cooling effect. Adding Equation (2) and Equation (3) gives the Vortex Tube performance equation as follows (Eq. 4):

$$
\Delta T=T_{h}-T_{c}
$$

- the cooling capacity which is defined as:

$$
\dot{Q}_{c}=\dot{m}_{c} \Delta h_{c}=\dot{m}_{c}\left(h_{i}-h_{c}\right)
$$

For the case of an ideal gas, the cooling capacity may be defined as:

$$
\dot{Q}_{c}=\dot{m}_{c} \Delta h_{c}=\dot{m}_{c} c_{p}\left(T_{i}-T_{c}\right)=\dot{m}_{c} c_{p} \Delta T_{c}
$$

- the isentropic efficiency as:

$$
\eta_{i s}=\frac{\Delta h_{c}}{\Delta h_{c s}}
$$

In which $\Delta h_{c s}$, is the maximum possible enthalpy drop for an isentropic expansion process. For an ideal gas, it can be defined as:

$$
\eta_{i s, i}=\frac{\Delta T_{c}}{\Delta T_{c s}}
$$

In which $\Delta T_{c s}$ isentropic temperature drop can be defined as follows:

$$
\Delta T_{c s}=T_{i}-T_{c s}=T_{i}\left[1-\left(\frac{P_{c}}{P_{i}}\right)^{(\gamma-1) / \gamma}\right]
$$

Considering the above definitions, the specific cooling capacity can be derived as follows:

$$
q_{c}=\frac{\dot{Q}_{c}}{\dot{m}_{i}}=\mu_{c} \Delta h_{c}=\mu_{c} \eta_{i s} \Delta h_{c s}
$$

\section{EXPERIMENTAL APPARATUS}

Figure 4 shows a schematic diagram of the experimental apparatus and measuring devices. High-pressure natural gas from the distribution pipeline is directed tangentially into the Vortex Tube. The high-pressure gas expands in the Vortex Tube and separates into cold and hot streams. The cold gas leaves the central orifice near the entrance nozzle, while the hot gas discharges from the periphery at the far end of the tube. The control valve is being used to control the flow rate of the hot stream. This would help to regulate cold mass friction. Two orifice flow meters, which were constructed according to ISO5167, are employed to measure the mass flow rate of the hot and cold streams. 3 PT100 temperature sensors are installed to measure inlet, and hot and cold stream temperatures. 2 pressure transmitters are utilised to quantify the inlet pressure and outlet pressure of hot streams.

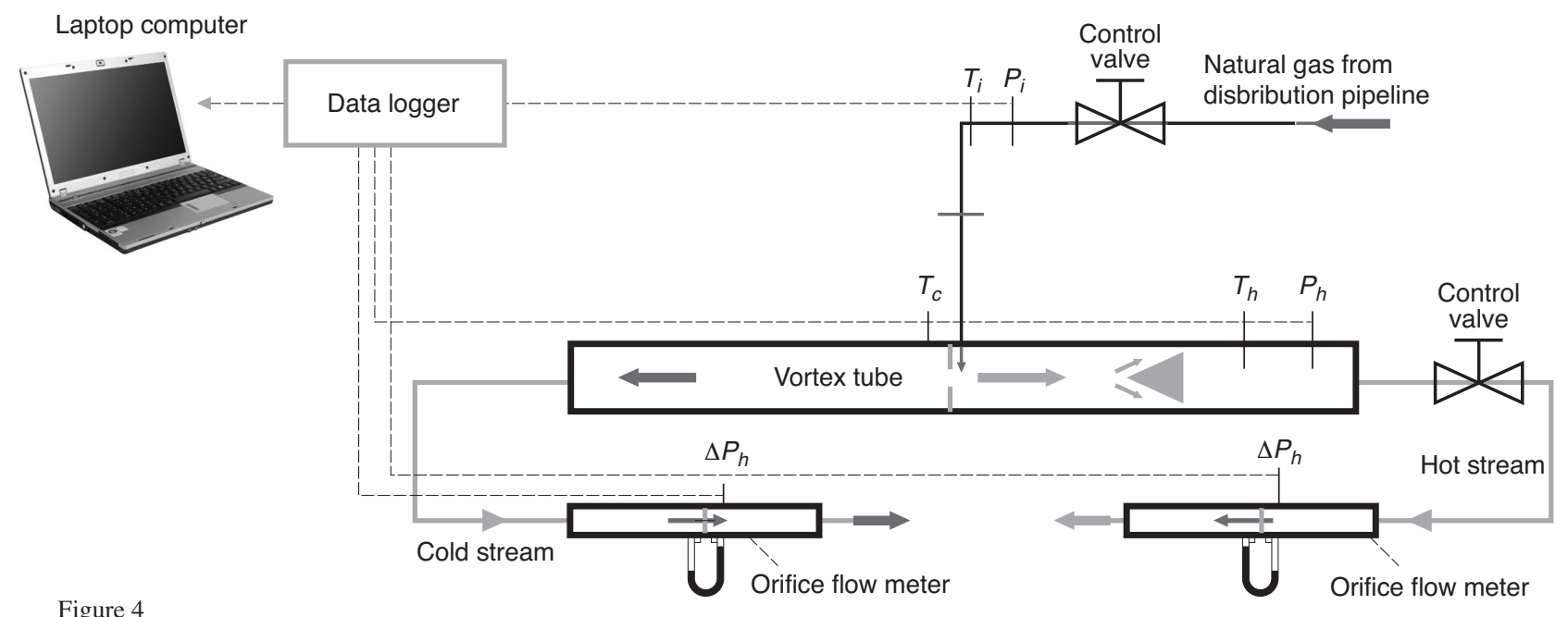

Figure 4

A schematic diagram of the experimental layout. 


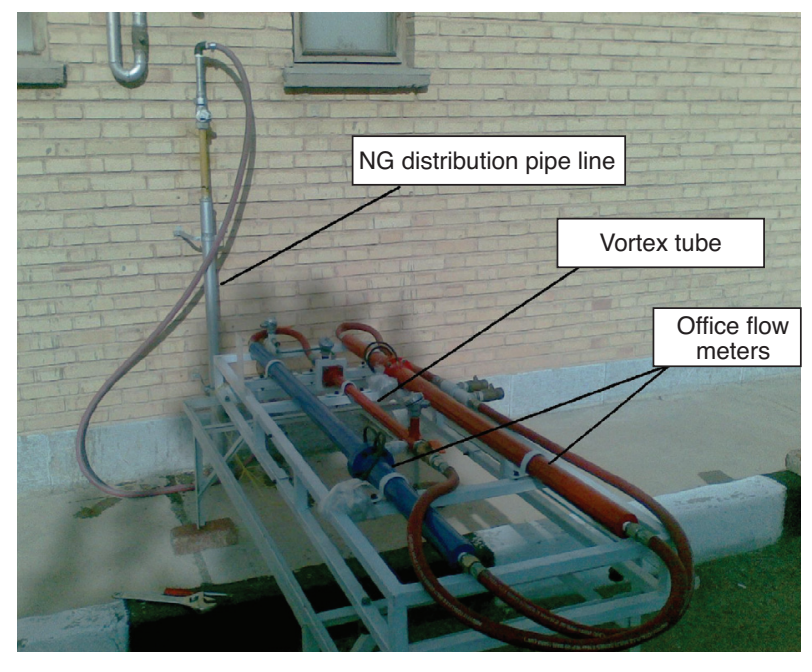

Figure 5

The experimental test bed in operation.

Figure 5 shows the experimental test bed in operation. The experiments were carried out in Shahrood University of Technology's main campus. As shown in the figure, the Vortex Tube was connected to the NG distribution pipeline using a flexible pipe. The inlet pressure did not vary during experiments and was 5 bar. In the figure, the hot length of the VT and hot stream flow meter are shown in red, while the cold length of the VT and cold stream flow meter are shown in blue. The VT was made from steel with an inlet diameter of $25 \mathrm{~mm}$. During the tests, the cold orifice diameter of the VT was varied among 3 available orifices as detailed in Table 2. It should also be pointed out that all tests were carried out at an inlet temperature of $5 \mathrm{bar}$, which is the absolute pressure within the NG distribution pipeline.

The experimental test bed was also moved to the Koolab Toos Company to investigate thermal separation of air as the working fluid. The company is able to provide a high quantity of air at constant high pressure. This enables one to compare results for NG and air for the same VT. In these cases, the inlet pressure was also set at 5 bar.

\section{ERROR ANALYSIS}

The errors associated with temperature measurements are computed in this section. The maximum possible errors in various measured parameters; namely, temperature and pressure, were estimated by using the method proposed by Moffat (1985). Errors were estimated from the minimum values of output and the accuracy of the instrument. This method is based on careful specification of the uncertainties in the various experimental measurements. If an estimated quantity, $Y$, depends on independent variables like $x_{i}$ then the error in the value of " $Y$ " is given by:

$$
\frac{\partial Y}{Y}=\sqrt{\sum_{1}^{n}\left(\frac{\partial x_{i}}{x_{i}}\right)^{2}}
$$

where $\frac{\partial x_{i}}{x_{i}}$ are the errors in the independent variables, $\partial x_{i}=$ accuracy of the measuring instrument, $x_{i}=$ minimum value of the output measured.

\subsection{Error in Temperature Measurement}

PT100 temperature sensors were used to measure the gas temperatures. Temperatures are logged directly in a file with accuracy of $0.1^{\circ} \mathrm{C}$. The maximum possible error in the case of temperature measurement was calculated from the minimum values of the temperatures measured and the accuracy of the instrument. The error in the temperature measurement is:

$\frac{\partial T}{T}=\sqrt{\left(\frac{\partial T_{P T 100}}{T_{\min }}\right)^{2}+\left(\frac{\partial T_{\log }}{T_{\min }}\right)^{2}}=\sqrt{\left(\frac{0.5}{12}\right)^{2}+\left(\frac{0.1}{12}\right)^{2}}=0.04=4 \%$

\subsection{Error in Pressure Measurement}

Pressure transmitters were used to measure the gas pressure. Pressures are logged directly in a file with accuracy of 0.01 bar. The error in the pressure measurement is:

$$
\frac{\partial P}{P}=\sqrt{\left(\frac{\partial P_{\text {tran }}}{P_{\min }}\right)^{2}+\left(\frac{\partial P_{\log }}{P_{\min }}\right)^{2}}=\sqrt{\left(\frac{0.01}{1.33}\right)^{2}+\left(\frac{0.01}{1.33}\right)^{2}}=0.01=1 \%
$$

\subsection{Error in Flow Rate Measurement}

Flow measurements were made using orifice flow meters. Uncertainty analysis was conducted according to the standard procedures reported in ISO5167. The analysis shows that the error in the flow rate measurement is $4.5 \%$.

\section{RESULTS AND DISCUSSION}

Figure 6 shows the effects of cold orifice diameter on cooling effects for NG as the working fluid. It can be seen that the cold orifice with $d=8 \mathrm{~mm}$ creates the highest cooling effects for lower $\mu_{c}$ and maximum temperature drop $(10 \mathrm{~K})$ at $\mu_{c} \approx 0.5$. At a higher value of $\mu_{c}$, it is the orifice with a diameter of $12 \mathrm{~mm}$ which produces higher cooling effects. It should also be pointed out that there is a specific $\mu_{c}$ (about 0.6) in each case which causes the temperature differences to be maximised. This confirms the findings of Orhan and Muzaffer (2006), as the cold fraction is an important parameter influencing the performance of the energy separation in the Vortex Tube. 


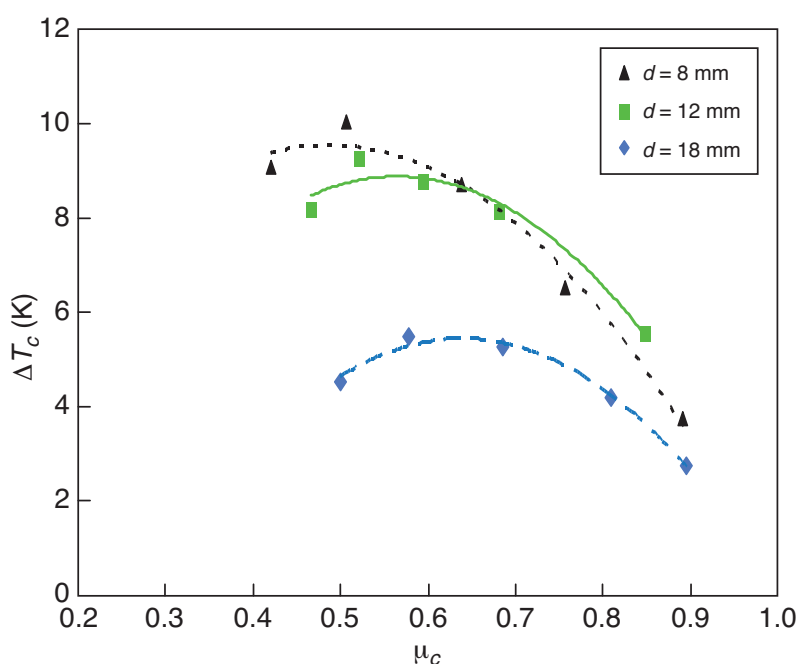

Figure 6

Effects of cold orifice diameter on cooling effects for NG.

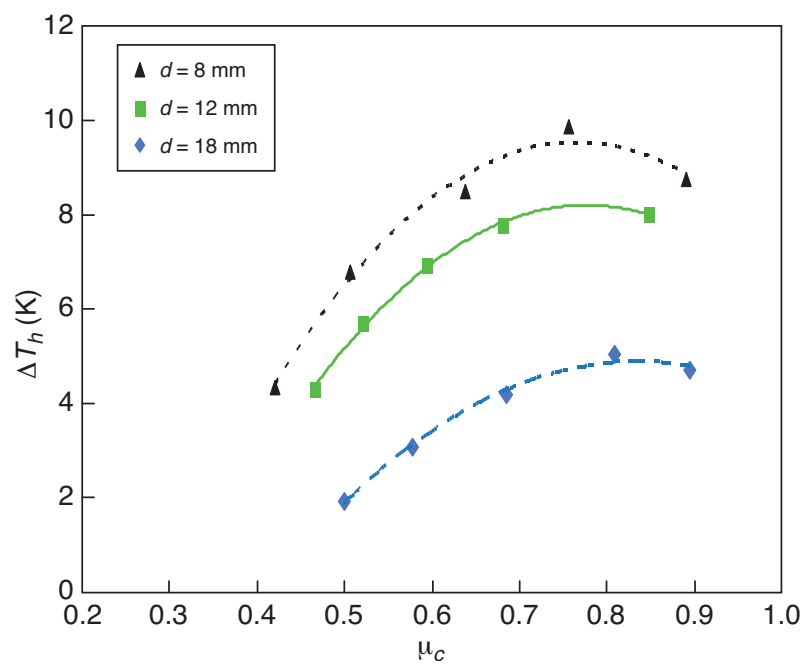

Figure 7

Effects of cold orifice diameter on heating effects for NG.

Figure 7 shows the effects of cold orifice diameter on heating effects for NG as the working fluid. It can be seen that the orifice with $d=8 \mathrm{~mm}$ creates the highest heating effects. It should also be pointed out there is a $\mu_{c}$ in each case which causes the temperature differences to be maximised. For the current configuration at $\mu_{c} \approx 0.7$ the highest heating effects are encountered. Again, it can be seen that the cold fraction has a big effect on energy separation and heating effects. Note that in Figures 6 and 7, the cold orifice diameter has a higher influence on heating effects than cooling effects.

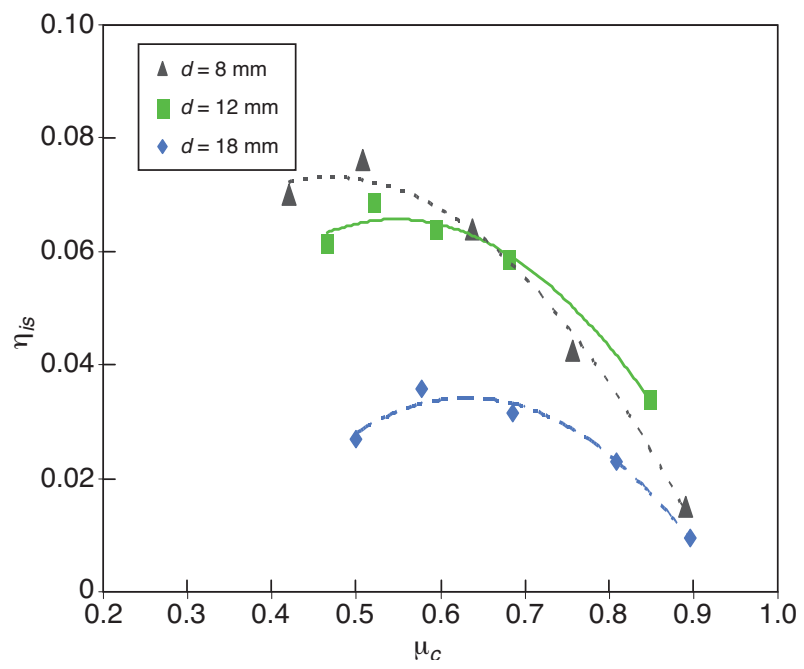

Figure 8

Effects of cold orifice diameter on isentropic efficiency for NG.

Figure 8 shows the effects of cold orifice diameter on isentropic efficiency for NG as the working fluid. It can be seen that the orifice with $d=8 \mathrm{~mm}$ creates the highest efficiency at $\mu_{c} \approx 0.5$. For the other orifices, the highest isentropic efficiency is reached at 0.55 and 0.6 cold friction. Below 0.6 cold friction, the orifice with $d=8 \mathrm{~mm}$ creates higher efficiency and above 0.6 cold friction, it is the orifice with $d=12 \mathrm{~mm}$.

Figure 9 shows the effects of cold orifice diameter on specific cooling capacity for NG as the working fluid.

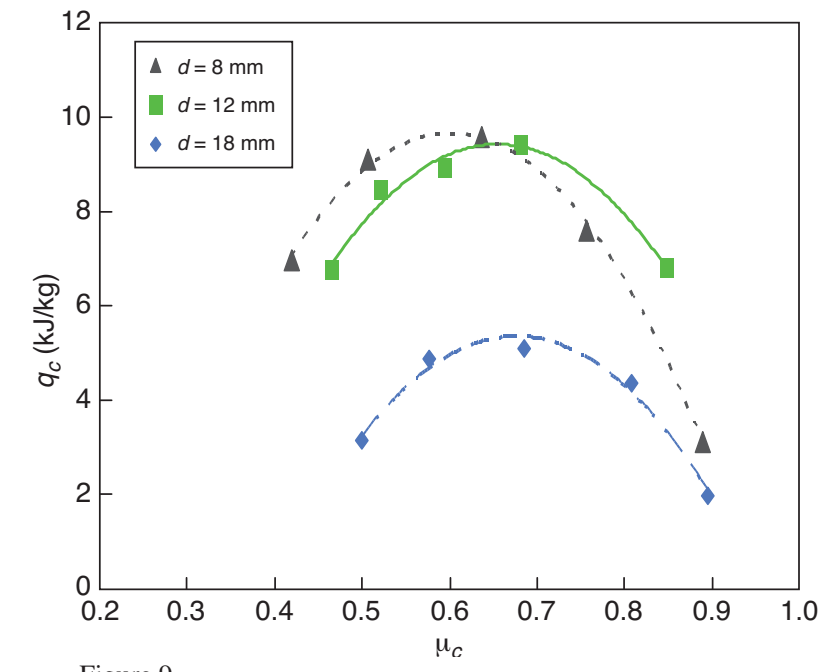

Figure 9

Effects of cold orifice diameter on specific cooling capacity for NG. 
It can be seen that the orifice with $d=8 \mathrm{~mm}$ creates the highest specific cooling capacity at $\mu_{c} \approx 0.6$, while the orifice with $d=12 \mathrm{~mm}$ creates about the same specific cooling capacity at $\mu_{c} \approx 0.7$. Nikolaev et al. (1995) found that the maximum refrigeration capacity of the Vortex Tube falls within the range from $60 \%$ to $70 \%$ cold fraction. Poshernev and Khodorkov (2003) mentioned that within their range of input parameters the refrigerating capacity has a distinct maximum at a cold fraction of about 50\%-60\%. Nimbalkar and Muller (2009) mentioned that the maximum value of the performance factor was always reachable at a $60 \%$ cold fraction irrespective of the orifice diameter. As can be seen in Figure 9, our results also show that maximum cooling capacity is encountered at about $65 \%$ cold fraction regardless of the orifice diameter. This phenomenon can be explained on the basis of pressure balance inside the Vortex Tube, discussed by Love (1974), and, Piralishvili and Fuzeeva (2005).

According to Eiamsa-ard and Promvonge (2008), at $d / D=0.5$, the optimised point should be reached for air as the working fluid. For the current configuration, it means $d=12.5 \mathrm{~mm}$ : the results show that the optimum value is between $d=8$ and $d=12 \mathrm{~mm}$ for NG as the working fluid.

Figure 10 shows a comparison between air and NG as the working fluid on the VT heating effects for $d=12 \mathrm{~mm}$. It can be seen that heating effects for air are much higher than for NG. This is probably due to Joule-Thomson effects which cause the temperature drop in NG to be higher than air, and consequently, heating effects for NG are lower than for air.

Figure 11 shows a comparison between air and NG as the working fluid on the VT cooling effects for $d=12 \mathrm{~mm}$. It can be seen that for $\mu_{c} \leq 0.65$ cooling effects for air are slightly higher than for NG, and for $\mu_{c} \geq 0.65$, NG cooling effects are slightly higher than air.

Figure 12 shows a comparison between air and NG as the working fluid on the VT specific cooling capacity for $d=12 \mathrm{~mm}$. It can be seen that the cooling capacity for NG is much higher than for air despite the higher cold temperature difference for air than NG. This is due to the higher specific heat capacity of NG than air.

For the current configuration, about a $10 \mathrm{~K}$ temperature drop (Fig. 6) is encountered and $10 \mathrm{~kJ} / \mathrm{kg}$ of refrigeration is created at the optimum point. However, it may not be high enough, but it would be quite possible to improve the VT performance by methods suggested by Wu et al. (2007) and Aydin and Baki (2006) to obtain a higher temperature drop and cooling capacity. They obtained a cold temperature difference of as much as $50 \mathrm{~K}$ for air at an inlet pressure of 5 bar. Saidi and Valipour (2003) have built a Vortex Tube with isentropic efficiency as high as $30 \%$.

Here, to study the effects of the VT isentropic efficiency on cold temperature drop and potential cooling capacity, it is assumed that it is possible to build a VT with higher efficiency. Firstly, by curve fitting a polynomial curve to the values of Figure 8 for $d=8$, the following equation could be obtained:

$$
\frac{\eta_{i s}}{\eta_{i s(\max )}}=11.113 \mu_{c}{ }^{3}-26.635 \mu_{c}^{2}+18.06 \mu_{c}-2.838
$$

Then the above equation could be employed to calculate the VT isentropic efficiency as a function of cold mass fraction and maximum VT isentropic efficiency. Once the isentropic efficiency is known, it would be an easy job to

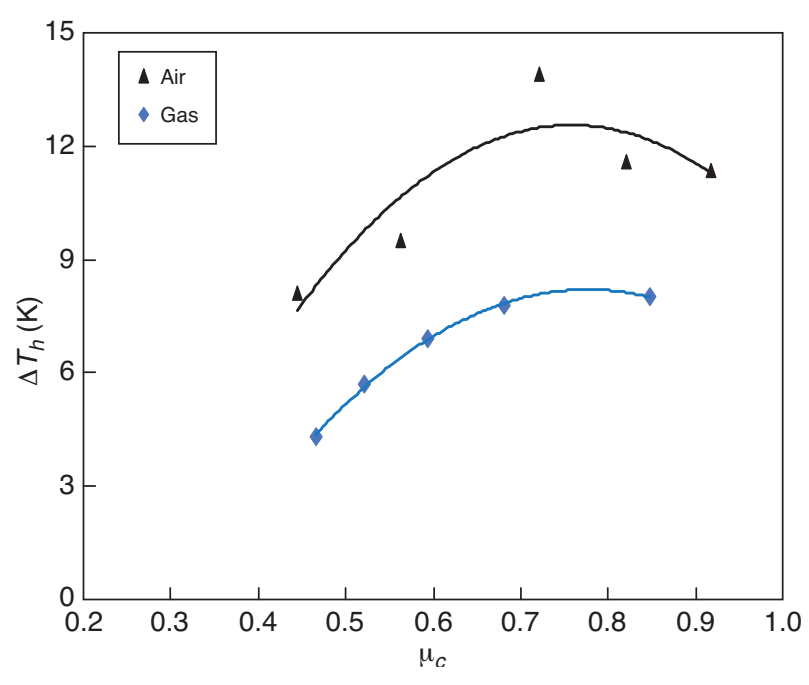

Figure 10

Comparing heating effects for NG and air when $d=12 \mathrm{~mm}$.

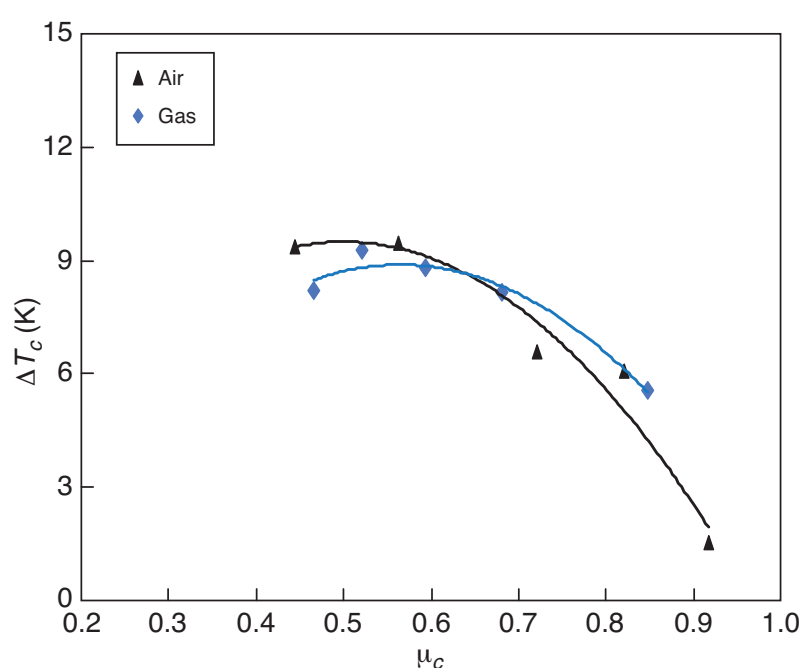

Figure 11

Comparing cooling effects for NG and air when $d=12 \mathrm{~mm}$. 


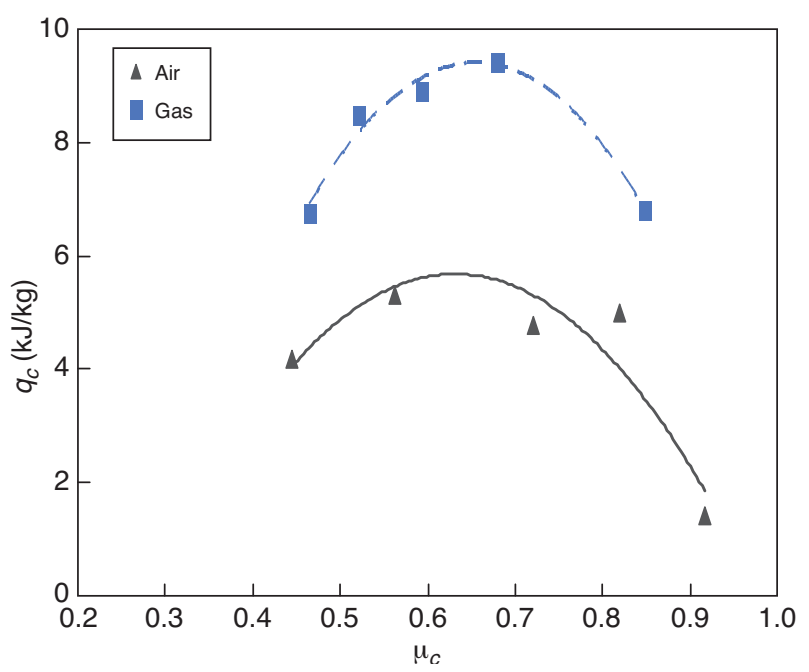

Figure 12

Comparing cooling capacity for NG and air when $L_{h}=769$.

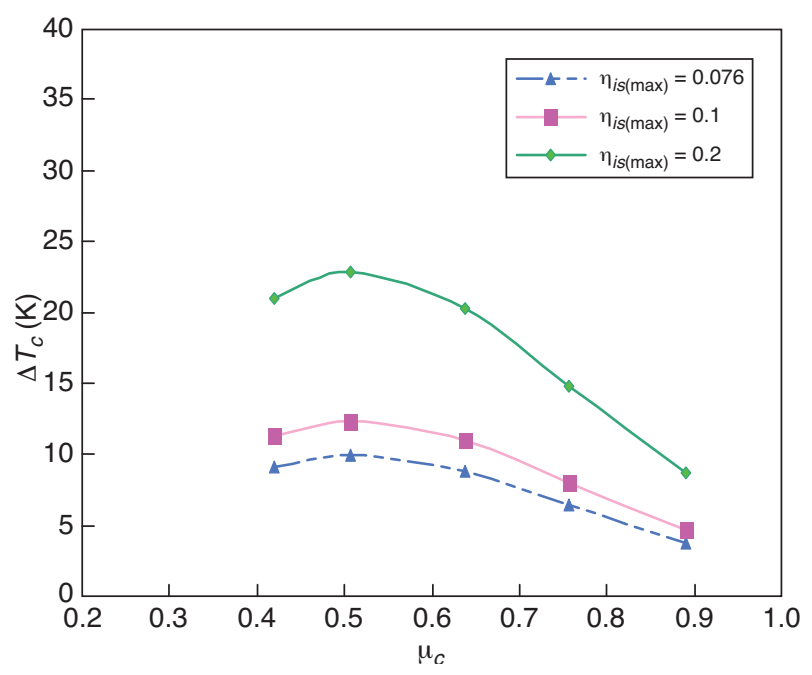

Figure 13

Effect of the VT isentropic efficiency on cooling effects.

calculate cold temperature difference by employing Equation (6) and the properties table of methane.

Figure 13 depicts the effects of the VT isentropic efficiency on cooling effects. It is obvious that the isentropic efficiency has a big influence on cooling effects and as the efficiency increases, the cooling effects increase too. Cooling effects in the order of $25 \mathrm{~K}$ could be obtained for $\eta_{i s} \approx 0.2$.

Figure 14 depicts the effect of the VT isentropic efficiency on specific cooling capacity. It is obvious that the isentropic efficiency has a big effect on cooling capacity. A cooling capacity as high as $25 \mathrm{~kJ} / \mathrm{kg}$ could be obtained for the obtainable value of $\eta_{i s} \approx 0.2$.

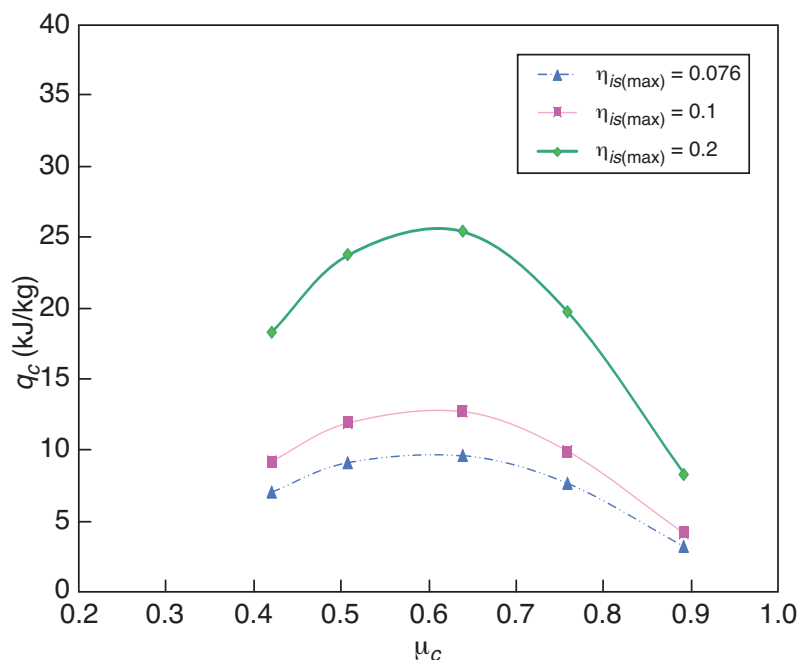

Figure 14

Effect of the VT isentropic efficiency on cooling capacity.

\section{CONCLUSIONS}

Natural gas is delivered to the customers through the distribution pipeline at approximately 5 bar, but all NG equipment consumes it at a working pressure of slightly higher than 1 bar. Currently, throttling valves are employed to reduce the pressure through a constant enthalpy process. During this pressure reduction, about $2 \mathrm{~K}$ temperature reduction can be expected. As the temperature reduction is not high enough, it is not feasible to take advantage of this pressure reduction. The VT is a potential candidate to replace the current system as a reliable system. In the case of replacement, it would be possible to produce refrigeration, especially for high consumers such as hotels and restaurants.

In this work an experimental study was carried out to investigate Natural Gas (NG) thermal behaviours in a VT. The effects of the VT cold orifice diameter on the VT thermal separation were also studied. Further, the amount of cooling capacity created by NG as it passes through a VT was calculated. Comparison was made for the thermal behaviour of the VT for air and NG as the working fluid.

The results show that the VT performance is maximised for a specific orifice diameter and cold fraction. An equation was obtained for the VT isentropic efficiency as a function of cold mass fraction. For the current study, the isentropic efficiency is calculated to be around 0.1 , which is lower compared with other authors such as Saidi and Valipour (2003). This causes the temperature drop to be around $10 \mathrm{~K}$ and cooling capacity to be around $10 \mathrm{~kJ} / \mathrm{kg}$. By improving the VT in order to obtain higher isentropic efficiency, as in Saidi and Valipour (2003), one could create a $25 \mathrm{~K}$ temperature drop and $25 \mathrm{~kJ} / \mathrm{kg}$ specific cooling capacity. This suggests that the 
VT could be a suitable candidate to replace current throttling valves. Employing the VT as suggested here would probably have a big impact on energy saving in the gas industry.

The heating effects for air are much higher than for NG. For cooling effects, the temperature difference for air is slightly higher than NG.

\section{ACKNOWLEDGEMENT}

This study was supported by the Semnan Gas Company (Iran). Special thanks also go to the Koolab Toos Company. The authors are also grateful to the reviewers of this paper for their time and valuable comments.

\section{REFERENCES}

Aljuwayhel N.F., Nellis G.F., Klein S.A. (2005) Parametric and internal study of the Vortex Tube using a CFD model, Int. J. Refrig. 28, 442-450.

Balmer R.T. (1998) Pressure-driven Ranque-Hilsch temperature separation in liquids, J. Fluid. Eng.-T. ASME 110, 161-164.

Cockerill T. (1995) The Ranque-Hilsch Vortex Tube, PhD Thesis, Cambridge University, Engineering Department, Sunderland.

Collins R.L., Lovelace R.B. (1997) Experimental study of twophase propane expanded through the Ranque-Hilsch Tube, J. Heat Trans.-T. ASME 101, 300-305.

Dincera K., Baskayab S., Uysalc B.Z., Ucguld I. (2009) Experimental investigation of the performance of a Ranque-Hilsch Vortex Tube with regard to a plug located at the hot outlet, Int. J. Refrig. 32, 87-94.

Eiamsa-ard S., Promvonge P. (2008) Review of Ranque-Hilsch effects in Vortex Tubes, Renew. Sust. Energ. Rev. 12, 1822-1842.

Hilsch R. (1947) The use of expansion of gases in a centrifugal field as a cooling process, Rev. Sci. Instrum. 18, 2, 108-113.

ISO-51671, Measurement of fluid flow by means of pressure differential devices inserted in circular-cross section conduits running full - Part 1: General principles and requirements; Part 2: Orifice plates.

Khodorkov L., Poshernev N.V., Zhidkov M.A. (2003) The Vortex Tube - a universal device for heating, cooling, cleaning, and drying gases and separating gas mixtures, Chem. Petrol. Eng. 39, 7-8, 409415 .

Kulkarni M.R., Sardesai C.R. (2002) Enrichment of Methane concentration via separation of gases using Vortex Tubes, J. Energ. Eng. 128, 1, 1-12.

Lin S., Chen J.R., Vatistas G.H. (1990) A heat transfer relation for swirl flow in a Vortex Tube, Can. J. Chem. Eng. 68, 6, 944-947.
Lewins J., Bejan A. (1995) Vortex Tube optimization theory, Energy 24, 931-943.

Love W.J. (1974) Prediction of pressure drops in straight Vortex Tube, AIAA J. 12, 7.

Moffat R.J. (1985) Using Uncertainty Analysis in the Planning of an Experiment, J. Fluid. Eng.-T. ASME 107, 173-178.

Nikolaev V.V., Ovchinnikov V.P., Zhidkov M.A. (1995) Experience from the operation of a variable Vortex Tube in a gas separating station, Gaz. Prom. 10, 13.

Nimbalkar S.U., Muller M.R. (2009) An experimental investigation of the optimum geometry for the cold end orifice of a Vortex Tube, Appl. Therm. Eng. 29, 509-514.

Orhan A., Baki Muzaffer (2006) An experimental study on the design parameters of a counterflow Vortex Tube, Energy 31, 2763 2772 .

Piralishvili S.A., Polyaev V.M. (1996) Flow and thermodynamic characteristics of energy separation in a double-circuit Vortex Tubean experimental investigation, Exp. Therm. Fluid Sci. 12, 4, 399410.

Piralishvili A., Fuzeeva A.A. (2005) Hydraulic characteristics of Ranque-Hilsch energy separators, High Temp. 43, 6, 900-907.

Poshernev N.V., Khodorkov I.L. (2004) Natural-gas tests on a Conical Vortex Tube (CVT) with external cooling, Chem. Petrol. Eng.+ 40, 3-4, 212-217.

Ranque G.J. (1993) Experiments on expansion in a Vortex with simultaneous exhaust of hot air and cold air, J. Phys. Radium (Paris) 4, 112-4 S-115. Also translated as General Electric Co., Schenectady Works Library 1947; T.F. 3294.

Ranque G.J. (1934) Method and apparatus for obtaining from a fluid under pressure two outputs of fluid at different temperatures, US patent 1:952,281.

Saidi M.H., Valipour M.S. (2003) Experimental modeling of Vortex Tube refrigerator, Appl. Therm. Eng. 23, 1971-1980, doi:10.1016/S1359-4311(03)00146-7.

Skye H.M., Nellis, G.F., Klein S.A. (2006) Comparison of CFD analysis to empirical data in a commercial Vortex Tube, Int. J. Refrig. 29, 71-80.

Silverman P.M. (1982) The Vortex Tube: a violation of the second law, Eur. J. Phys. 3, 88-92.

Stephan K., Lin S., Durst M., Huang F., Seher D. (1983) An investigation of energy separation in a Vortex Tube, Int. J. Heat Mass Tran. 26, 341-348.

Takahama H., Kawamura H., Kato S., Yokosawa H. (1979) Performance characteristics of energy separation in a steam-operated Vortex Tube, Int.J.Eng. Sci. 17, 735-744.

Wu Y.T. et al. (2007) Modification and experimental research on Vortex Tube, Int. J. Refrigeration, doi:10.1016/j.ijrefrig.2007.01.013.

Final manuscript received in August 2009 Published online in October 2010 